\title{
INVESTIGATING THE ADVERSE IMPACTS OF RURAL ROADS USING A FUZZY MULTICRITERIA APPROACH
}

\author{
Vineet TIRTH ${ }^{1,2}$, Makrand WAGALE ${ }^{3}$, Ajit Pratap SINGH ${ }^{\circledR}{ }^{3}$, Ashoke Kumar SARKAR ${ }^{4}$, \\ Ram Karan SINGH ${ }^{5}$, Ali ALGAHTANI ${ }^{1,2}$, Saiful ISLAM ${ }^{6}$ \\ ${ }^{1}$ Mechanical Engineering Department, College of Engineering, King Khalid University, \\ Abha-61411, Asir, Kingdom of Saudi Arabia \\ ${ }^{2}$ Research Center for Advanced Materials Science (RCAMS), King Khalid University \\ Guraiger, Abha-61413, Asir, Kingdom of Saudi Arabia \\ ${ }^{3}$ Civil Engineering Department, Birla Institute of Technology and Science, Pilani - 333031, India \\ ${ }^{4}$ Department of Civil Engineering, Indian Institute of Technology, Jammu, India \\ ${ }^{5}$ Department of Civil and Environmental Engineering, The NorthCap University, Gurugram, \\ Haryana-122017, India \\ ${ }^{6}$ Civil Engineering Department, College of Engineering, King Khalid University, Abha-61411, \\ Asir, Kingdom of Saudi Arabia
}

Received 7 November 2020; accepted 24 May 2021

\begin{abstract}
Rural roads contribute significantly to the living conditions of rural populations. However, they also lead to detrimental impacts on physical and social environments. In this context, the present study proposes a novel fuzzy multicriteria approach that amalgamates fuzzy TOPSIS and an improved fuzzy weighted average method to assess the negative impacts on physical and social environments, due to rural road construction. The approach offers a structured comprehension and incorporates detailed criteria that reflect the adverse effects. The attributes identified and assessed in this study are air quality, vegetation cover status, noise pollution, transmissible disease, habits/behaviour, safety and security, and road accidents. The approach includes both qualitative and quantitative data from focus group discussions. The results presented here are essential to identify corrective actions, promote effective distribution of funds, and facilitate effective decisionmaking for sustainable rural development.
\end{abstract}

Keywords: accidents, adverse impact assessment, rural development, roads construction, fuzzy TOPSIS.

\section{Introduction}

Rural roads are extensively considered to be an effective instrument in poverty alleviation at rural areas. They are a lifeline to raise the living standards of rural population. Improved rural roads generate new and enhanced linkages to nearby markets by reducing travel time and travel costs (Van de Walle, 2009). Improved rural road infrastructure facilitates access to social services (e.g., health services and education facilities), thereby enhancing social outcomes. They play a vital role in generating employment opportunities for rural communities through integrated road networks (Gachassin et al., 2010; Rand, 2011). Rural roads significantly assist in distributing services to rural inhabitants (Aderamo \& Magaji, 2010) and provide numerous income opportunities (Kanuganti et al., 2017; Labi et al.,
2019). They influence the income diversification process by facilitating non-farm employments opportunities for rural inhabitants (Abur et al., 2015).

Improved rural roads allow access to technology and encourage rural inhabitants' involvement in income-earning activities (Binswanger et al., 1993; Aggarwal, 2018). The enhancement of rural roads reduces the transportation costs of agricultural goods, thereby increasing the earnings of rural inhabitants (Tunde \& Adeniyi, 2012). Rural roads also assist rural inhabitants to withstand economic shocks and significantly influence their social status. Particularly at drought-prone areas, rural roads serve two primary goals: 1) they help in the movement of agricultural produce from farms to local markets during sur-

${ }^{*}$ Corresponding author. E-mail: aps@pilani.bits-pilani.ac.in 
plus times, and 2) they serve as a medium for the transfer of foodstuff and other aid in times of drought (Asif, 2012). Studies have also stated that rural transport infrastructure paves access to agricultural produce markets of the rural community and have assisted in increasing their production of agricultural goods (Berechman, 2009; AsomaniBoateng et al., 2015).

The evidence from the literature as discussed above shows that rural transportation infrastructure facilitates rural economic growth with improvements in living standards of rural inhabitants, which can be measured in terms of improvement in transport services, health, and educational facilities accessible to rural areas (Hine et al., 2019). An improved rural road enhances access to educational facilities by reducing travel distances and travel times to such facilities. It, therefore, encourages school enrolment among target populations (Muralidharan \& Prakash, 2017), and influences the provision of new schools. In addition, rural roads improve potential access to health care facilities (Rand, 2011; Wondemu \& Weiss, 2012; Kanuganti et al., 2016). With improved road conditions, rural inhabitants, particularly women, can access health facilities.

Several studies have addressed the impact of rural road construction (Wagale et al., 2019a, 2019b). They presented the contribution of roads to social and economic development. Rural roads improve mobility as well as access to essential services and market centres, and stimulate non-farm activities and alteration in land use and crop diversification (Van de Walle, 2009). Improved better rural roads enhance social outcomes by facilitating access to social services such as education and health facilities. This is actualized in terms of an increase in the number of school-going children due to reduced travel time to reach the facility (Khandker et al., 2009). The same holds in the case of access to a health facility; individuals can access to health due to good road connectivity (Porter, 2012; Tunde \& Adeniyi, 2012; Kanuganti et al., 2017; Wagale \& Singh, 2019). It has been found that rural roads have contributed significantly to the upliftment of rural life. Also, rural inhabitants have greater access to education with a reduced travel time.

Although there are positive outcomes of the construction of rural roads, there are also possibilities that they may have some negative impacts on the physical environment and target populations. Keeping in view the positive effects of the construction of roads identified in the literature, the scope of the present paper is set to specify different criteria and sub-criteria which address their negative impacts on society. These criteria and sub-criteria may be in terms of consequences, for example, disturbance of the natural environment, soil erosion, increase in air pollution, etc. When the condition of rural roads is improved, it can potentially attract more traffic, leading to an increase in the number of accidents and localized air pollution (Desapriya et al., 2012). It has been determined that casualty accidents are more sensitive to the traffic volume and pavement condition in rural roads than their sensitivity concerning design or operational aspects (Chen et al., 2019). Improved roads offer a better level of service concerning the speed of vehicles, resulting in higher accident rates (Saeed et al., 2019).

Considering the various adverse effects discussed above, the paper investigates and assesses multiple factors contributing to adverse impacts (degradation of rural road construction's physical and social environment). The study explores the adverse effects of rural road construction on target populations. It identifies the most negatively impacted attributes among the six chosen attributes, namely, road accidents, transmissible diseases, ill habits/behavior, safety and security, air quality, and noise pollution. These attributes represent both the physical and social environment. The study presented in this article provides the groundwork for the concerned decision-makers to assess and mitigate the impacts (negative) induced by the construction of rural roads, particularly those constructed under Pradhan Mantri Grameen Sadak Yojana (PMGSY), thus, helping them to achieve their intended goal of sustainable rural development.

The paper is structured as follows: Section 1 introduces the study and discusses the literature and the need for the study. Section 2 elaborates on the methodology, followed by a brief description of the study area and data collection. Section 3 briefly illustrates the procedure of the proposed methods. Section 4 presents the practicality of the proposed model through results and discussions for the case study, followed by Sections 5 and 6 that discuss the sensitivity analysis and conclusions.

\section{Literature review}

Contemporary literature addresses mostly the impacts of rural road construction on the physical environment. Rural road construction may negatively affect indigenous animal and plant species; it may significantly affect the physical features at landscape levels (Forman \& Alexander, 1998; Trombulak \& Frissel, 2000). Due to road improvement, traffic volume on these roads is likely to increase, thereby creating noise and air pollution and disrupting the sensitive wildlife and ecological balance. This may cause the emission of contaminants (e.g., engine oils, fuels, carbon dioxide, and other chemicals) and degrade the effectiveness of the habitat (Luce \& Wemple, 2001; Madej, 2001). Other adverse effects of rural road construction are deforestation, fragmentation of landscapes, increase in landslides, the spread of species that may bring disease to wildlife and fauna, and deplete wildlife through subsistence hunting (Daigle, 2010). Deforestation is caused by land conversion or an increase in the harvesting of natural resources (to supply urban markets). The development of road infrastructure leads to an increase in land settlements which thereby intensifies agricultural activities. This often leads to further encroachment of more forest land. With further increase in the inventory of roads, there is a decline in the forest cover along with the road proximity (Hine et al., 2019). 
Rural roads have also been considered ideal passageways for transmission of diseases and decline in the local population's health through the possible cause of contamination of local water supply (Tsunokawa \& Hoban, 1997). Increased mobility through roads can encourage the transmission of communicable diseases, including sexually transmitted diseases (STDs) (Mashiri, 2004; Morris \& Ferguson, 2006). A study by Feldacker et al. (2011) in rural Malawi showed that with improved rural road networks, the spread of STDs, including human immunodeficiency virus (HIV), among both genders (men and women) increases considerably. Apart from these adverse impacts of rural roads, there is a likely increase in the safety concern of the target population. As in the case of developing countries, rural roads consist of mixed traffic: pedestrian, non-motorized, and motorized traffic. The volume of motorized traffic is considerably lower compared to the other two components. However, due to improved road conditions, there are possibilities of increasing in motor vehicles making pedestrian and non-motorized traffic vulnerable to accidents and injury (Desapriya et al., 2012; Chen et al., 2017). The rate of accidents across all road types is higher in the case of rural roads. One reason is the obstruction of sight. Obstruction of sight due to crops varies by crop type and season; drivers may not have the required visibility about the potential risks and are bound to take few precautions (i.e., lowering the vehicle's speed) to avoid crashes. Thus, it leads to accidents of higher severity (Hall \& Tarko, 2019). From the literature discussed above, it is understood that most of the studies have addressed only the adverse impacts of road construction on the physical environment. Therefore, this creates a need to explore and develop a model that amalgamates the effects of rural road construction on both the physical and social environment.

According to contemporary literature, approaches commonly used for assessing the impacts (positive) of rural road construction are experimental designs, quasiexperimental designs, qualitative approaches, and multicriteria decision-making approach. However, the experimental design (randomization technique) is considered the most suitable. The main feature of this technique is the assessment of the effectiveness of the development program by comparing the expected impacts of the target population with that of the control population. This is achieved by selecting the target population and control population randomly. However, it would be erroneous to rely entirely on such random selection (Barnow \& King, 2000). Nonetheless, in quasi-experimental and qualitative approaches, they suffer from bias issues (Suresh, 2011; Lopera et al., 2017; Wagale et al., 2021). Therefore, the multi-criteria decision-making (MCDM) approach is excellent for identifying and assessing the negative impact factors of rural road construction.

The MCDM approach offers formulations that reflect institutional or policy constraints, which can typically be expressed in terms of performance criteria such as budget/cost constraint and thresholds such as facility condi- tion. Specifically, the multiple-criteria decision-making approach simplifies the decision-making process by facilitating the process in a distinct, realistic, and justifiable manner. It allows the decision-makers to analyze and investigate the trade-offs among performance criteria (Sinha \& Labi, 2011). The approach considers various courses of action, which are difficult to assess using single and simple dimensions (Chen et al., 2015). In the MCDM technique, the attributes contributing to the problem are identified and are ranked based on their relative significance.

The literature suggests various MCDM techniques that can be employed to assess the impacts of rural road construction. Among these, the mainly used techniques are the Analytical Hierarchy Process (AHP), Elimination Et Choix Traduisant la Realite (ELECTRE III), and Preference Ranking Organization Method for Enrichment Evaluations (PROMETHEE) (Wagale et al., 2019a, 2019b). These techniques focus on identifying as well as ranking the factors that have been impacted by road construction. Among all the MCDM techniques, AHP has been used many times for assessing the impacts, but this method suffers from some weaknesses, which must be addressed. For example, it suffers from the problem of non-uniqueness in results (i.e., inconsistency induced in the assessment process due to pair-wise comparison, and there may be a possibility of a reversal in the order of ranks of the attributes/factors considered for the assessment when any attribute is eliminated or added) (Wang et al., 2009; Wagale \& Singh, 2019). Furthermore, it requires a considerable amount of computational data based on probability and possibility assessment measures. Therefore, this may lead to incorrect interpretation of the results. Although the MCDM approaches are accepted as an effective tool to deal with impact assessments, they nevertheless possess certain shortcomings, for example, incapable of accounting for imprecision and vagueness in the data, which require fuzzy integrated MCDM approaches.

To date, no study has reported on the application of fuzzy MCDM approaches to assess the negative impacts of rural road construction. Methods including fuzzy TOPSIS, fuzzy Delphi, and improved fuzzy weighted average (IFWA) can overcome the limitations of conventional MCDM techniques. Therefore, a novel coherent evaluation methodology is proposed in this study. It is based on fuzzy TOPSIS and improved fuzzy weighted average methods. From a practical applicability viewpoint, the proposed model can handle complexities by exploiting the needed information perceived and comprehended from the stakeholders and will help concerned decisionmakers to initiate necessary corrective actions to mitigate the substantial negative impacts.

\section{Methodology}

The present study proposes a novel model to assess the attributes contributing to the negative impacts of road construction for rural habitations. The steps followed in the study are outlined below: 
Step 1: It deals with the identification and selection of the rural road stretches. In the present study, rural roads belonging to six different divisional blocks of the Jhunjhunu district of Rajasthan state, India, were identified, constructed under the PMGSY program. The program is meant to connect small villages and habitations to the nearest marketplace or the major road connectivity. It is then followed by the assimilation of attributes and features negatively impacting rural road construction. These are identified based on the literature reviewed. They are finally validated using the opinion of experts at research institutes and those that work in rural development.

Step 2: It follows a preliminary field survey through site inspection, followed by a focused survey. Data collection through focus group surveys were carried out from March to April 2018 for the selected PMGSY road stretches. A total of 27 focus group discussions were performed. Data on the physical and social environments were collected.

Step 3: It assesses the data collected for the attributes using the proposed model, which helps to identify the attributes based on their relative significance. Further, sensitivity analysis was performed to determine the influence level of the attributes and to assess the developed model's robustness. The steps followed in the study are depicted in Figure 1.

\subsection{Case study and data collection}

Data for the study were collected through focus group discussions from March to April 2018 from 27 connectivities, distributed in six different divisional blocks of the Jhunj-

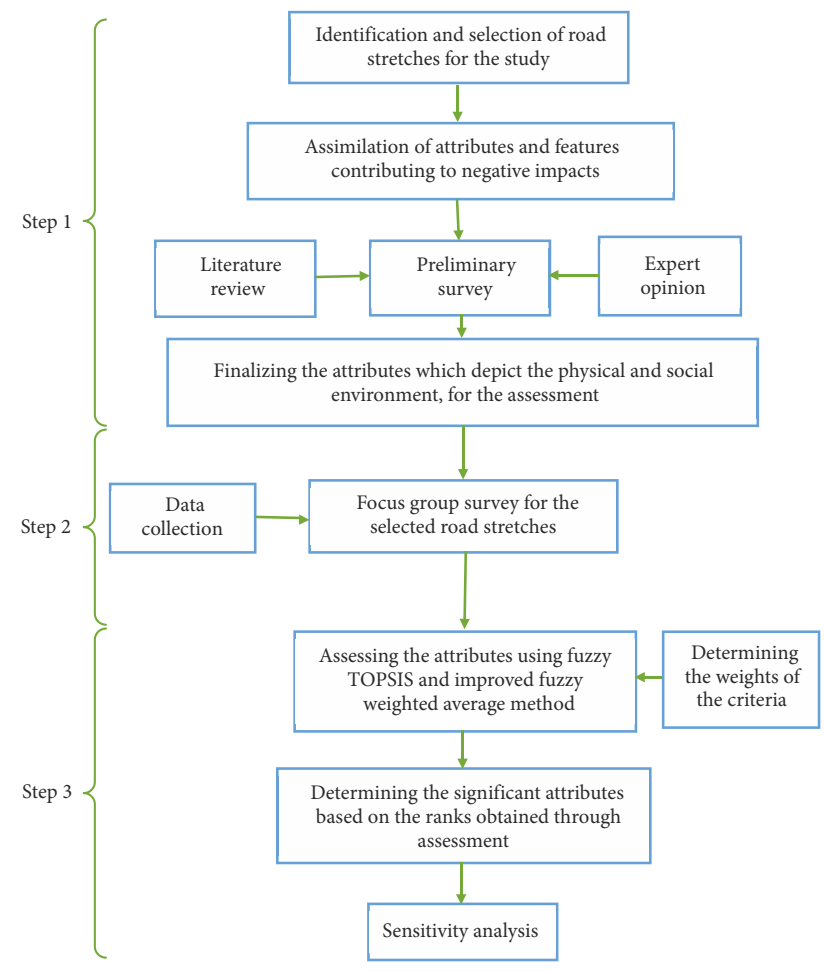

Figure 1. The methodology of the study hunu district of Rajasthan, India, given in Table 1. To have the proper comprehension of the attributes and features to be selected for the study, available literature (Tsunokawa \& Hoban, 1997) was reviewed, followed by discussions with experts. Furthermore, a preliminary survey and discussions with village representatives were also performed to identify significant attributes and features. Thus, six attributes that contribute most to the negative impacts of rural road construction were identified, namely, road accidents, transmissible diseases, ill habits/behavior, safety and security, air quality, and noise pollution (Table 2).

Data were collected to assess the significance of the attributes/features qualitatively using the questionnaire. To prevent error in the data, an attempt was made to facilitate feedback from the participants at the end of the focus group discussion. Figure 2 represents the study area considered for the research.

Table 1. Habitations and blocks of the study area

\begin{tabular}{|c|c|}
\hline Habitations & Block \\
\hline Bhagatia Ki Dhani $^{*}$ & \multirow{4}{*}{ Buhana } \\
\hline Dangiyo Ki Dhani & \\
\hline Sahali Ki Dhani & \\
\hline Khantato Ki Dhani & \\
\hline Bugaliyon Ki Dhani & \multirow{5}{*}{ Jhunjhunu } \\
\hline Jatan Wali ${ }^{* *}$ & \\
\hline Dhani Syolpura & \\
\hline Dhani Dalchinasi & \\
\hline Dhani Khojiyon Ki & \\
\hline Bissa Wali & \multirow{5}{*}{ Khetri } \\
\hline Dhani Adhana Ki & \\
\hline Dhani Bagadiya & \\
\hline Guwada wala Badh Ki & \\
\hline Rawatala & \\
\hline Ranveenpura & \multirow{2}{*}{ Nawalgarh } \\
\hline Triloka Ki Dhani & \\
\hline Maondia Ki Dhani & \multirow{5}{*}{ Surajgarh } \\
\hline Khatiyo Ki Dhani & \\
\hline Hukma Ki Dhani & \\
\hline Nirwano ki Dhani & \\
\hline Charan ki Dhani & \\
\hline Kalala Kahar Dhani & \multirow{6}{*}{ Udaipurwati } \\
\hline Ciroth Kkala Rodala Dhani & \\
\hline Kakar ki Dhani Nehra & \\
\hline Dulaniya & \\
\hline Balajijoda Prema ki Dhani Mandana & \\
\hline Mukand Deepchand Madiya & \\
\hline
\end{tabular}

Notes: ${ }^{*}$ Dhani: A Dhani is the smallest clusters of houses wherein most living families are relatives of each other or at least are of the same caste); ${ }^{* *}$ Jatan wali: A small village/hamlet wherein most living families are relatives of each other or are of the same caste, viz., Jatan). 
Table 2. Attributes and features contributing to adverse impacts of rural road construction

\begin{tabular}{|l|c|l|}
\hline \multicolumn{1}{|c|}{ Attribute } & Symbol & \multicolumn{1}{c|}{ Feature } \\
\hline Status of behavior/habits & $\mathrm{S}_{\mathrm{B}}$ & Increased consumption of alcohol, use of drugs, involvement in illegal activities \\
\hline Status of road accidents & $\mathrm{S}_{\mathrm{A}}$ & Speeding of vehicles, drinking and driving, no signboards, faulty road geometrics \\
\hline Status of safety and security & $\mathrm{S}_{\mathrm{SS}}$ & Thefts and burglaries \\
\hline Status of transmissible diseases & $\mathrm{S}_{\mathrm{TD}}$ & Increased vulnerability to communicable diseases like STDs \\
\hline Status of noise pollution & $\mathrm{S}_{\mathrm{NP}}$ & Increase in vehicular traffic, easy access of loudspeakers \\
\hline Status of air quality (dust particles) & $\mathrm{S}_{\mathrm{AQ}}$ & Increase in vehicular traffic \\
\hline
\end{tabular}

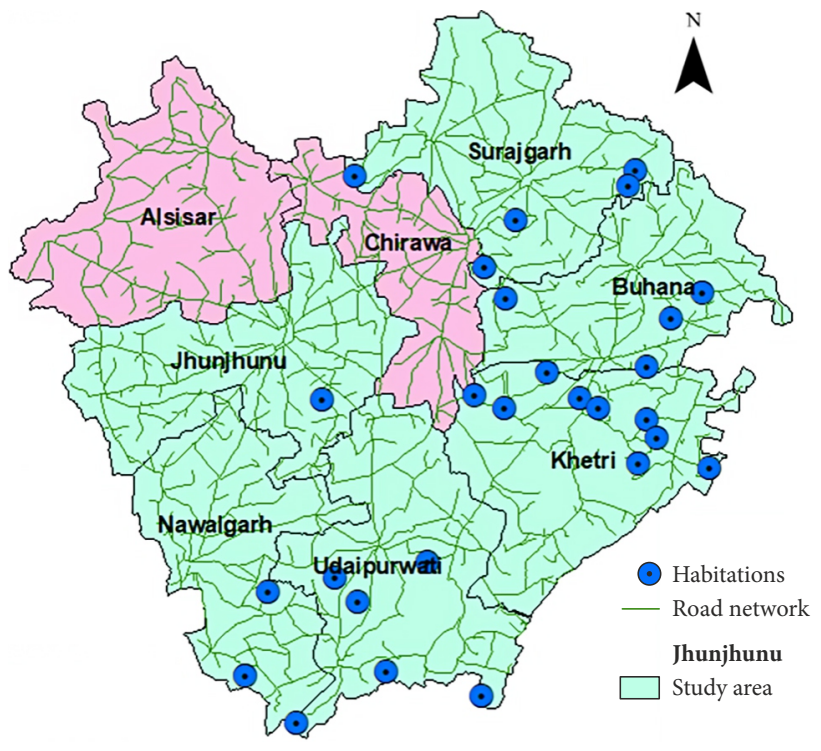

Figure 2. The geographical location of Habitations in Jhunjhunu District of Rajasthan, India

\section{Data analysis}

Evaluation of attributes contributing to the negative impacts based on their relative significance helps concerned decision-makers to identify the potential aspects which are undesirable from the point of view of rural development. It assists them in implementing essential plans that help mitigating those unwanted effects of road construction and enhance the conditions of rural households. Assessment of these attributes is a multi-criteria decision-making problem. In this study, fuzzy TOPSIS and improved fuzzy weighted average method (IFWA) have been employed to assess the data. The techniques have been chosen because crisp data are inadequate in real-life modelling problems. Data collected are based upon human perception, which is often inaccurate and vague and cannot be assessed using precise numerical value (Bellman \& Zadeh, 1970; Chen \& Hsieh, 2000; Singh et al., 2019).

\subsection{Application of fuzzy TOPSIS approach}

Assessing the negative impacts of rural road construction through focus group discussion involves participants as decision-makers. The data collected usually is in the form of linguistic judgments rather than crisp values. This helps enumerators to capture the data in a fuzzy state. A few studies have introduced the concept of fuzzy theory to improve such MCDM problems. Among such fuzzy MCDM methods, fuzzy TOPSIS is one such technique that considers the uncertainty of human cognition and vague judgments (Chen et al., 2015; Kahraman et al., 2007). The fuzzy TOPSIS approach considers the shortcomings of earlier proposed methods effectively. It can overcome the disadvantages of pairwise comparison between criteria/sub-criteria and alternatives to be evaluated (Liang \& Meng, 2019). The present study, therefore, used the fuzzy TOPSIS (see Figure 3) approach proposed by Chen et al. (2015). The systematic step-wise procedure followed to evaluate the relative significance of the attributes/features is illustrated below. The hierarchy structure of the attributes for criteria considered for the study is shown in Figure 4.

The algorithm of fuzzy TOPSIS is enlisted step-wise below:

Step 1: In this step, the important attributes contributing to the negative impacts of road construction are identified. They are assessed for conditions before and after the construction of rural (PMGSY) roads. Further, the attribute ratings are transformed from a linguistic scale to a fuzzy number to obtain a fuzzy judgment matrix. In this study triangular fuzzy number was used. Figure 5 depicts the fuzzy membership scale used in the study to illustrate the attribute ratings. Table 3 elucidates the linguistic variables adopted for the study. The fuzzy scale was decided based on opinions obtained from the experts working in rural development and research institutes. Table 4 summarizes the linguistic ratings given by the experts in terms of the criteria.

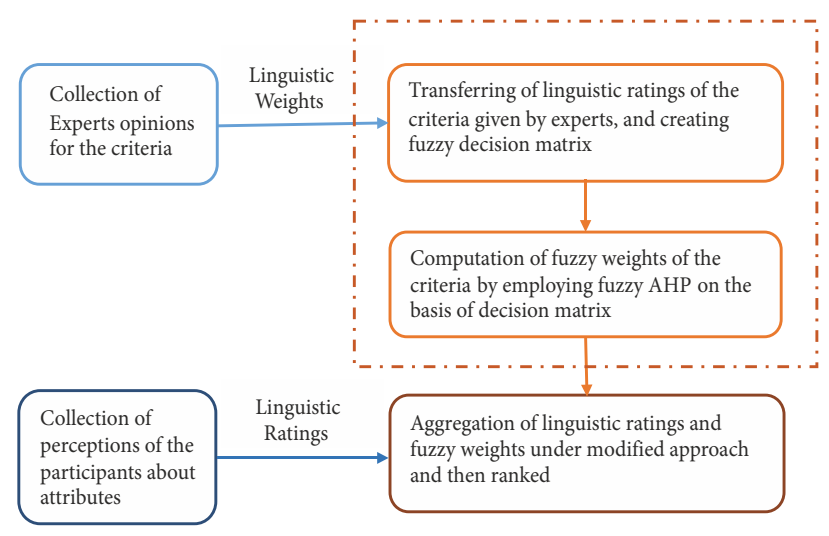

Figure 3. Chen's fuzzy TOPSIS framework 


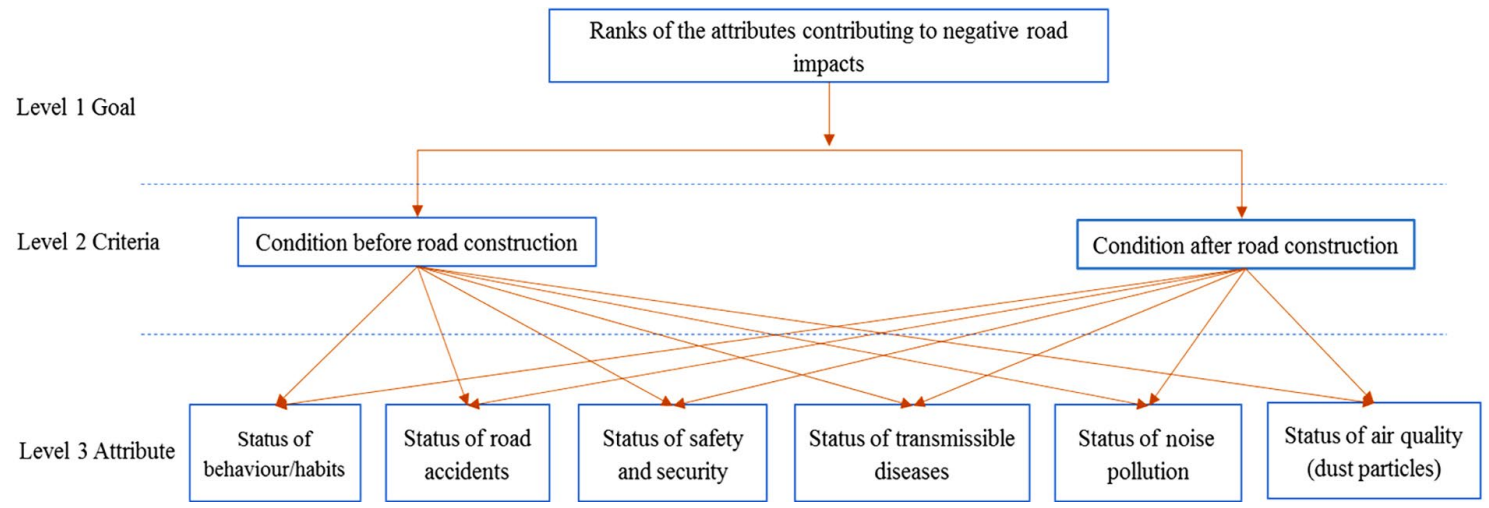

Figure 4. Hierarchy structure for evaluating the negative impacts of rural road construction

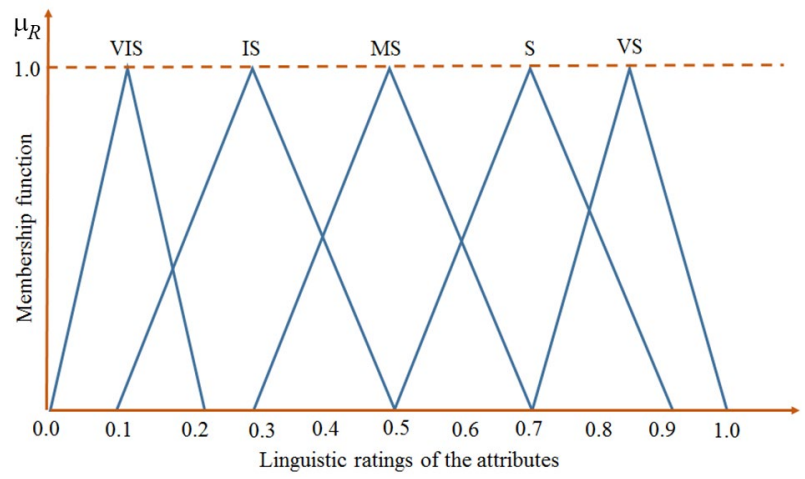

Table 3. Fuzzy numbers defining linguistic ratings for the attributes

Figure 5. Membership scale for attribute ratings

Table 4. Linguistic ratings of the criteria given by the experts

\begin{tabular}{|l|c|c|c|c|c|}
\hline \multicolumn{1}{|c|}{ Criteria } & Expert 1 & Expert 2 & Expert 3 & Expert 4 & Expert 5 \\
\hline Condition before road construction & VS & MS & MS & S & MS \\
\hline Condition after road construction & S & S & S & VS & S \\
\hline
\end{tabular}

Step 2: This step follows the assessment of comparative importance weights. In this study, two criteria for the negative aspects, that is, the condition before the road construction and condition after road construction, were considered. The study uses a fuzzy analytical hierarchy process (FAHP) to assess the comparative importance of weight. For example, the linguistic rating for the condition before road construction criteria given by each of the five experts are (S, S, S, VS, S). Then, the geometric mean fuzzy comparison value obtained for this criterion is $\left(\tilde{r}_{1}=\right.$ $0.61,0.68,0.79)$. Further, the fuzzy weight $\widetilde{\left(w_{2}\right.}=0.25$, $0.32,0.42$ ) for this criterion is obtained using Eqn (1). Finally, the crisp weight is obtained using geometric mean integration representation (GMIR) as 0.324 . Table 5 shows the weights obtained for the "Condition before road construction" and "Condition after road construction" criteria.

$$
\widetilde{w_{2}}=\left(\tilde{r_{1}} \otimes \widetilde{r_{2}}\right)^{-1},
$$

where $\tilde{a}_{11}, \tilde{a}_{12}$ are the fuzzy comparison values obtained based on linguistic ratings of the experts.
Table 5. Weights of the criteria

\begin{tabular}{|l|c|}
\hline \multicolumn{1}{|c|}{ Criteria } & Weight \\
\hline Condition before road construction & 0.324 \\
\hline Condition after road construction & 0.639 \\
\hline
\end{tabular}

Step 3: In this step, the mean fuzzy dominance rating of attributes/ features for criteria is evaluated. Let, $D_{i c}^{f}=\left(C_{i c}^{f}\right.$, $\left.A_{i c}^{f}, B_{i c} f\right)$ is the fuzzy dominance rating of the $i^{\text {th }}$ attribute about the $c^{\text {th }}$ subjective criteria, evaluated by the $f^{\text {th }}$ focus group, where $(i=1, \ldots, m ; c=1, \ldots, p ; f=1, \ldots, n)$. The mean fuzzy dominance rating of the $i^{\text {th }}$ attribute about the $c^{\text {th }}$ subjective aspect evaluated by the $f^{\text {th }}$ focus-group is evaluated as given in Eqn (2):

$$
\left[\frac{\sum_{f=1}^{n} C_{i c}^{f}}{n}, \frac{\sum_{f=1}^{n} A_{i c}^{f}}{n}, \frac{\sum_{f=1}^{n} B_{i c}^{f}}{n}\right] \text {. }
$$

Step 4: This step follows the computation of ideal and nadir solutions. The ideal and nadir solutions are assessed based on comparative proximity. They are observed as 
the distance of attributes $i$ for the ideal (nadir) solutions (Liang \& Meng, 2019). If the attributes are positive, the standardized fuzzy dominance rating $D_{i j}$ (max) of the $i^{\text {th }}$ sub-criteria for aspect $j$ is evaluated as shown in Eqn (3), where $\Delta_{j}=\max \left(B_{i j}\right)$.

$$
D_{i j}=\left(l_{i j}, m_{i j}, k_{i j}\right)=\left[\frac{C_{i j}}{\Delta_{j}}, \frac{A_{i j}}{\Delta_{j}}, \frac{B_{i j}}{\Delta_{j}}\right] .
$$

If the attributes are negative, the standardized fuzzy dominance rating $D_{i j}$ is defined as shown in Eqn (4):

$$
D_{i j}=\left(\frac{\gamma_{i j}}{C_{i j}}, \frac{\gamma_{i j}}{A_{i j}}, \frac{\gamma_{i j}}{B_{i j}}\right),
$$

where $\gamma_{j}$ is $\min \left(B_{i j}\right)$.

Therefore, the fuzzy ideal and nadir solutions are determined by employing the representation vale $R\left(d_{i j}\right)$ and are finally defined as:

Fuzzy ideal solution $(\mathrm{I})=\left(D_{1}^{+}, D_{2}^{+}, \ldots, D_{j}^{+}, \ldots, D_{c}^{+}\right)$and

Fuzzy nadir solution $(\mathrm{N})=\left(D_{1}^{-}, D_{2}^{-}, \ldots, D_{j}^{-}, \ldots, D_{c}^{-}\right)$, respectively.

Table 6 shows the fuzzy ideal and nadir solutions obtained for an attribute with respect to criteria.

Step 5: In this step, the distance of attributes is computed with respect to the fuzzy ideal (I) and fuzzy nadir (N) solutions by employing Eqn (5) and Eqn (6) as shown below. Table 7 shows the distance of attributes with respect to IS and NS, respectively.

$$
\begin{aligned}
& d_{i}^{+}=\sqrt{\sum_{j=1}^{c}\left[\left(\beta_{j}\right)^{2} \times\left(\alpha_{M} \times\left(D_{j}^{+}, D_{i j}\right)\right)^{2}\right]} ; \\
& d_{i}^{-}=\sqrt{\sum_{j=1}^{c}\left[\left(\beta_{j}\right)^{2} \times\left(\alpha_{M} \times\left(D_{j}^{-}, D_{i j}\right)\right)^{2}\right]},
\end{aligned}
$$

where: $d_{i}^{+}$and $d_{i}^{-}$represent the distance of attribute from I and N; $\alpha_{M}$ is the integrated weight of the attribute; $\beta_{j}$ is the distance between two fuzzy numbers.

Step 6: This step follows the computation of a comparative estimate of attributes with respect to the ideal solution and raking them accordingly. Table 8 below depicts the comparative assessment of the attributes and their ranks. The comparative estimate $\left(C E^{*}\right)$ of the attribute with respect to the fuzzy ideal solution is evaluated using Eqn (7):

$$
C E^{*}=\frac{d_{i}^{-}}{d_{i}^{+}+d_{i}^{-}} \text {. }
$$

Table 7. The distance of the attributes with respect to IS and NS

\begin{tabular}{|l|c|c|}
\hline \multicolumn{1}{|c|}{ Attribute } & $d_{i}^{+}$ & $d_{i}^{-}$ \\
\hline Status of behavior/habits & 0.441 & 0.541 \\
\hline Status of road accidents & 0.439 & 0.544 \\
\hline Status of safety and security & 0.448 & 0.537 \\
\hline Status of transmissible diseases & 0.563 & 0.518 \\
\hline Status of noise pollution & 0.467 & 0.527 \\
\hline Status of air quality (dust particles) & 0.534 & 0.515 \\
\hline
\end{tabular}

Table 8. Comparative estimate and ranks of the attributes

\begin{tabular}{|l|c|c|}
\hline \multicolumn{1}{|c|}{ Attribute } & $C E^{*}$ & Rank \\
\hline Status of behavior/habits & 0.550 & 2 \\
\hline Status of road accidents & 0.553 & 1 \\
\hline Status of safety and security & 0.545 & 3 \\
\hline Status of transmissible diseases & 0.479 & 6 \\
\hline Status of noise pollution & 0.530 & 4 \\
\hline Status of air quality (dust particles) & 0.490 & 5 \\
\hline
\end{tabular}

\subsection{Application of improved fuzzy weighted average (IFWA) approach based on left and right score}

To evaluate the relative significance of the attributes contributing to the negative impacts of road construction, the second approach used in the study is the improved fuzzy weighted average (IFWA) method. This approach was used to compare the ranks obtained from the fuzzy TOPSIS approach. The procedure followed for the proposed approach is described as follows.

Step 1: It deals with the construction of a fuzzy decision matrix and a fuzzy weight matrix. In this step, the data obtained in linguistic terms for both ratings and weights of the attributes are transformed into a fuzzy scale. The membership scale corresponding to linguistic ratings is constructed accordingly. Using a particular shape of the membership function depends upon various factors, that is, the range of the data set (i.e., input and output), the grade of assessment, and the impact on the given attribute, and the opinion of the experts. In the present study, the triangular membership function was used due to its simplicity. It can also deal with cases where limited relevant information about the linguistic expressions are available as it overlaps and produces zero reconstruction error (Pe-

Table 6. Fuzzy ideal and nadir solutions of an attribute with respect to criteria

\begin{tabular}{|l|c|c|c|c|c|c|}
\hline \multicolumn{1}{|c|}{ Attribute } & \multicolumn{2}{c|}{ Condition before road construction } & \multicolumn{4}{c|}{ Condition after road construction } \\
\hline Status of behavior/habits & 0.150 & 0.207 & 0.330 & 0.210 & 0.283 & 0.474 \\
\hline Status of road accidents & 0.161 & 0.204 & 0.309 & 0.200 & 0.262 & 0.411 \\
\hline Status of safety and security & 0.160 & 0.223 & 0.366 & 0.210 & 0.291 & 0.486 \\
\hline Status of transmissible diseases & 0.263 & 0.406 & 0.958 & 0.310 & 0.468 & 1.000 \\
\hline Status of noise pollution & 0.182 & 0.262 & 0.479 & 0.220 & 0.321 & 0.578 \\
\hline Status of air quality (dust particles) & 0.244 & 0.375 & 0.848 & 0.260 & 0.381 & 0.711 \\
\hline
\end{tabular}


drycz, 1994). The fuzzy scale employed for both ratings and weights of the attributes is given in Table 3. This fuzzy scale has been decided based on the opinions of the experts working in the field of road safety audits and road safety management.

Step 2: This step follows the normalization of the fuzzy weight matrix of the criteria.

If $\tilde{w}_{i j}=\left(l_{i j}, m_{i j}, n_{i j}\right)(i=1,2, \ldots, k)$ represents the weight rating given by the $f^{\text {th }}$ expert, then in case of adverse criteria. In that case, the normalization of the weights is achieved using the mathematical expression shown in Eqn (8):

$$
\left(\tilde{w}_{i j}\right)_{N r}=\left(\frac{n_{i j}-n_{i j}^{\max }}{\Delta_{\max }^{\min }}, \frac{m_{i j}-n_{i j}^{\max }}{\Delta_{\max }^{\min }}, \frac{l_{i j}-n_{i j}^{\max }}{\Delta_{\max }^{\min }}\right),
$$

where $i=1,2, \ldots, k ; j \in c_{-} ; c_{-}$corresponds to the set of adverse criteria in the overall objective of the problem; $n_{j}^{\max }=\max \left(n_{i j}\right), l_{j}^{\min }=\min \left(l_{i j}\right), i=1,2, \ldots, k$; $\Delta_{\max }^{\min }=l_{j}^{\min }-n_{i}^{\max }$.

Step 3: In this step, the left and right scores for both weights of the attributes' criteria and their ratings are obtained. These are evaluated using Eqns (9) and (10):

$$
\begin{aligned}
& \left(L_{s c}\right)_{N r}=\left(\frac{\left(m_{i j}\right)_{N r}}{1+\left(m_{i j}\right)_{N r}-\left(l_{i j}\right)_{N r}}\right) ; \\
& \left(R_{s c}\right)_{N r}=\left(\frac{\left(n_{i j}\right)_{N r}}{1+\left(n_{i j}\right)_{N r}-\left(m_{i j}\right)_{N r}}\right) .
\end{aligned}
$$

Step 4: This step involves the construction of left and right score matrices for both ratings of the attribute (as Eqn (11)) and weight of the criteria (as Eqn (12)) as shown below. Figure 6 is the graphical visualization of the concept of the right and left scores. Table 9 and Table 10 show the left and right scores achieved for both attributes and criteria.

$$
\begin{aligned}
& \left(\left(L_{s c}\right)_{N r},\left(R_{s c}\right)_{N r}\right)_{A}= \\
& \left(\begin{array}{ccccc}
{\left[\left(L_{s c}\right),\left(R_{s c}\right)\right]_{11}} & \cdots & {\left[\left(L_{s c}\right),\left(R_{s c}\right)\right]_{1 j}} & \cdots & {\left[\left(L_{s c}\right),\left(R_{s c}\right)\right]_{1 p}} \\
\vdots & \ddots & \vdots & \ddots & \vdots \\
{\left[\left(L_{s c}\right),\left(R_{s c}\right)\right]_{i 1}} & \cdots & {\left[\left(L_{s c}\right),\left(R_{s c}\right)\right]_{i j}} & \cdots & {\left[\left(L_{s c}\right),\left(R_{s c}\right)\right]_{i p}} \\
\vdots & \ddots & \vdots & \ddots & \vdots \\
{\left[\left(L_{s c}\right),\left(R_{s c}\right)\right]_{k 1}} & \cdots & {\left[\left(L_{s c}\right),\left(R_{s c}\right)\right]_{k j}} & \cdots & {\left[\left(L_{s c}\right),\left(R_{s c}\right)\right]_{k p}}
\end{array}\right)
\end{aligned}
$$

$$
\begin{aligned}
& \left(\left(L_{s c}\right)_{N r},\left(R_{s c}\right)_{N r}\right)_{C W}= \\
& \left([ ( L _ { s c } ) , ( R _ { s c } ) ] _ { 1 } \cdots \left[\begin{array}{lll}
\left.\left(L_{s c}\right),\left(R_{s c}\right)\right]_{j} & \cdots & \left.\left[\left(L_{s c}\right),\left(R_{s c}\right)\right]_{p}\right) .
\end{array}\right.\right.
\end{aligned}
$$

Step 5: In this step, the fuzzy weighted average for each attribute is calculated and is expressed as the interval of

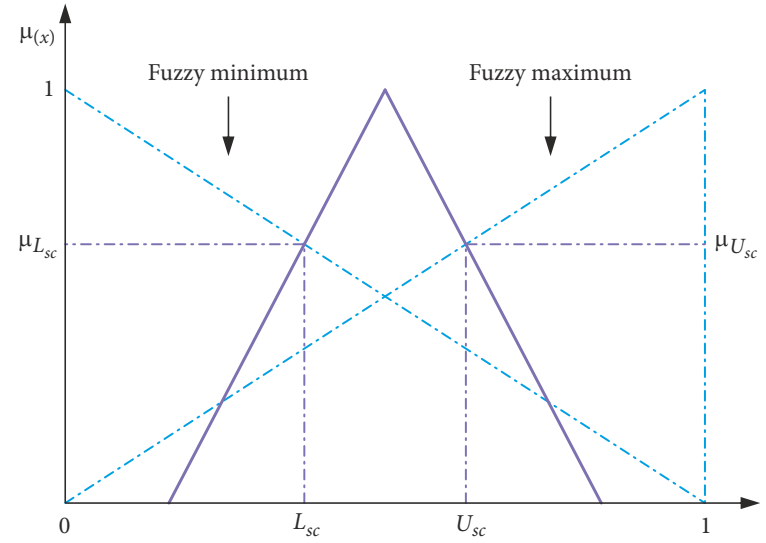

Figure 6. The concept of $\left[\left(L_{s c}, R_{s c}\right)\right]$

Table 9. Left and right interval ratings of the attribute

\begin{tabular}{|l|c|c|c|c|}
\hline \multicolumn{1}{|c|}{ Attribute } & \multicolumn{2}{|c|}{$\begin{array}{c}\text { Condition before } \\
\text { road construction }\end{array}$} & \multicolumn{2}{c|}{$\begin{array}{c}\text { Condition after road } \\
\text { construction }\end{array}$} \\
\hline $\begin{array}{l}\text { Status of } \\
\text { behavior/habits }\end{array}$ & 0.443 & 0.603 & 0.402 & 0.559 \\
\hline $\begin{array}{l}\text { Status of road } \\
\text { accidents }\end{array}$ & 0.455 & 0.601 & 0.439 & 0.592 \\
\hline $\begin{array}{l}\text { Status of safety } \\
\text { and security }\end{array}$ & 0.413 & 0.572 & 0.396 & 0.552 \\
\hline $\begin{array}{l}\text { Status of noise } \\
\text { pollution }\end{array}$ & 0.234 & 0.369 & 0.253 & 0.388 \\
\hline $\begin{array}{l}\text { Status of } \\
\text { transmissible } \\
\text { diseases }\end{array}$ & 0.352 & 0.511 & 0.358 & 0.517 \\
\hline $\begin{array}{l}\text { Status of air } \\
\text { quality (dust } \\
\text { particles) }\end{array}$ & 0.252 & 0.392 & 0.308 & 0.449 \\
\hline
\end{tabular}

Table 10. Left and right interval ratings for the weights of the criteria

\begin{tabular}{|l|c|c|}
\hline \multicolumn{1}{|c|}{ Criteria } & $\left(L_{s c}\right)_{N r}$ & $\left(R_{s c}\right)_{N r}$ \\
\hline Condition before road construction & 1.250 & 1.260 \\
\hline Condition after road construction & 0.857 & 0.939 \\
\hline
\end{tabular}

lower and upper bound value as $\left[\left(\theta_{i}\right)^{L b},\left(\theta_{i}\right)^{U b}\right]$. Let the left and right scores for an attribute for both rating and weight be $r_{i j}=\left[\left(L_{s c}, R_{s c}\right)_{i j}\right]$ and for the weight as $w_{j}=\left[\left(L_{s c}, R_{s c}\right)_{j}\right]$, therefore the fuzzy weighted average for the attribute in terms of upper bound value is expressed as below in Eqn (13). Table 11 shows the lower and upper bound values for the attributes.

$$
(\theta)_{i}=\left(\frac{w_{1} \times r_{i 1}+w_{2} \times r_{i 2}+\ldots+w_{p} \times r_{i p}}{w_{1}+w_{2}+\ldots+w_{p}}\right),
$$

where $i=1,2, \ldots, k$ and $\left(L_{s c}\right)_{j} \leq w_{j} \leq\left(R_{s c}\right)_{j}, j=1,2, \ldots$, $p,\left(L_{s c}\right)_{i j} \leq r_{i j} \leq\left(R_{s c}\right)_{i j}, j=1,2, \ldots, p$. 
Table 11. Lower and upper bound values for the attribute

\begin{tabular}{|l|l|l|}
\hline \multicolumn{1}{|c|}{ Attribute } & $\left(\theta_{i}\right)^{L b}$ & $\left(\theta_{i}\right)^{U b}$ \\
\hline Status of behavior/habits & 0.426 & 0.573 \\
\hline Status of road accidents & 0.448 & 0.595 \\
\hline Status of safety and security & 0.406 & 0.558 \\
\hline Status of noise pollution & 0.242 & 0.382 \\
\hline Status of transmissible diseases & 0.355 & 0.515 \\
\hline Status of air quality (dust particles) & 0.275 & 0.431 \\
\hline
\end{tabular}

Step 6: In this step, the final score of the attribute is calculated as the average of the lower and upper bound value of the attribute (as given in Table 12), which is then employed to rank the attributes. It is calculated as shown in Eqn (14):

$$
\left(\theta_{i}\right)_{A V G}=\left(\frac{\left(\theta_{i}\right)^{L b}+\left(\theta_{i}\right)^{U b}}{2}\right) .
$$

Table 12. Average IFWA value related to lower and upper bound interval

\begin{tabular}{|l|c|c|}
\hline \multicolumn{1}{|c|}{ Attribute } & $\left(\theta_{i}\right)_{A V G}$ & Ranks \\
\hline Status of behavior/habits & 0.500 & 2 \\
\hline Status of road accidents & 0.521 & 1 \\
\hline Status of safety and security & 0.482 & 3 \\
\hline Status of noise pollution & 0.435 & 4 \\
\hline Status of transmissible diseases & 0.312 & 6 \\
\hline Status of air quality (dust particles) & 0.353 & 5 \\
\hline
\end{tabular}

\section{Results and discussion}

The data were collected through a questionnaire for the participants belonging to focus groups. It was presumed that there might be variation in the data collected for different participants, as they may have different viewpoints on adverse outcomes of the constructed rural roads. However, it was observed that the perceptions of the other participants show little variation in their perspectives. Considering this, assessment has been performed by taking all the participants as one data set. During the focus group discussion, it was observed that the participants expressed a sense of insecurity during the period subsequent to the rural road improvement. It reveals that the most negative impact that has been materialized is the possibility of minor accidents, which are quite often with a high number of occurrences. In contrast, the chances of major accidents are low compared to minor accidents.

The habitations connected by these road connectives have none of the facilities such as schools, markets, hospitals within the locality, thus, making the inhabitants travel long distances to reach them. Most of the inhabitants usually prefer two-wheelers or bicycles for traveling, apart from other local public transport facilities. In some cases, it is observed that the inhabitants travel by walking if the distance to reach the nearest facility is low, thereby increasing the vulnerability of such pedestrians to crashes. However, the study is focused only on assessing the exposure and vulnerability of the inhabitants along the selected road stretches. The data were collected for attributes, namely, the status of road accidents, transmissible diseases, ill habits/behaviour, safety and security, air quality, and noise pollution. The final scores and the ranks for each of the attributes assessed are shown in Figure 7. The attributes are ranked in terms of their relative significance. To determine their relative importance, the proposed methodology employs fuzzy TOPSIS and improved FWA techniques.

The study observes that road accident criteria must have high priority as the primary attribute contributing to the negative impacts due to the construction of rural (PMGSY) roads. The reason could be inadequate and faulty designs of junctions as well as road geometry. Rural road connectivities have lower traffic volume, but the risk of an accident increases when these connectivities meet roads of high traffic intensity and volume. It has been perceived during data collection in the case of selected road connectives that road junctions have poor designs (i.e., turning radii, improper flaring of roadsides, etc.) accompanied by poor illumination and lack of speed signboards. Besides the road junction, road alignment has also been a significant concern that contributes to a road accident. The factors such as the shoulder's width vary throughout the road connectivity for most of the selected road stretches. Furthermore, the transition from the curved section to a straight section of the road alignment is observed to be uneven. It is prominently observed, particularly in a road stretch connecting Charan ki Dhani and Jatan wali habitations.

It is also found that the number of sharp horizontal curves along the road stretches is quite high, thereby increasing the risk of road accidents significantly. Besides the status of road accident attributes, the status of behaviours/habits and safety and security are significant, contributing to the adverse impacts. This is because the improvement in connectivity to nearest towns or markets will probably make the rural youth involved in unhealthy social activities, thereby changing the social environment of the habitations. Also, some of these roads pass crosssectional through the habitations to connect the nearest economic centres, thus, increasing the vulnerability of inhabitants in terms of safety and security to a significant extent. This was observed in the case of $40 \%$ of selected road stretches. It is substantiated by the inhabitants' feedback during a focus group discussion that there has been about a $30 \%$ increase in the theft and burgling activities that have increased safety concerns.

Apart from this, it can also be observed from Figure 7 that the status of transmissible diseases was deduced as an insignificant attribute. The cause might be due to the awareness within the rural community, and maybe the inhabitants are not keen and comfortable sharing this information as this might cause issues related to the pride 


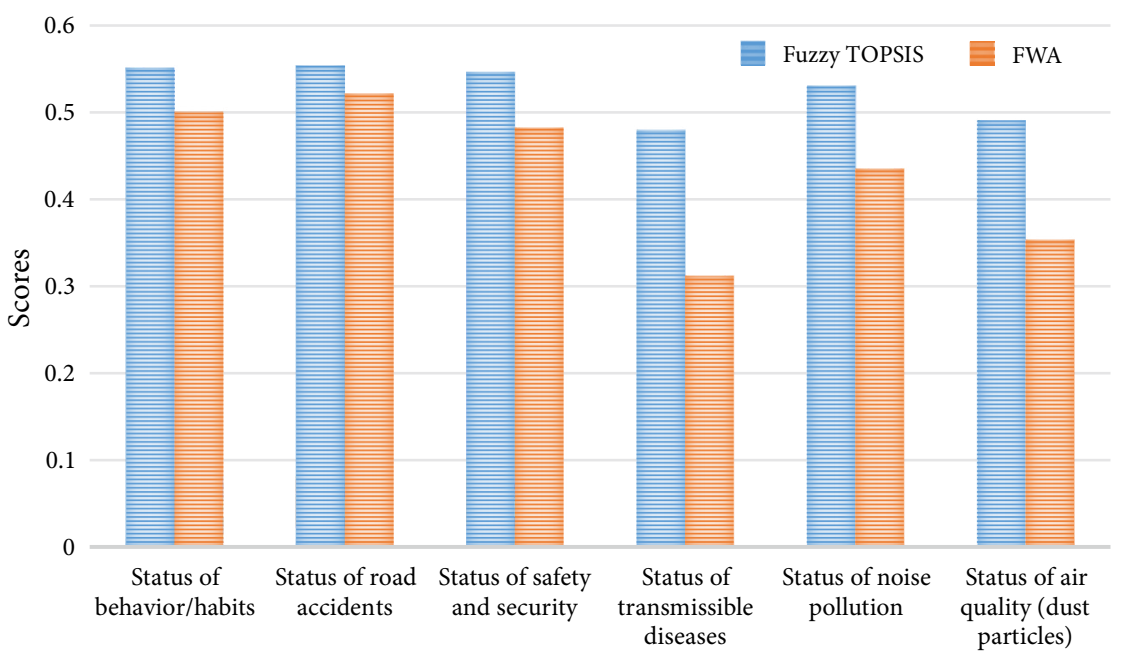

Rural road attributes

Figure 7. Attribute scores depicting their ranks for fuzzy TOPSIS and improved FWA

of the individual or household. Therefore, the ranking of attributes based upon their relative importance helps taking necessary corrective actions and reduce the possible negative impacts instigated by the road construction.

\section{Sensitivity analysis}

To facilitate a comprehensive understanding of the results obtained from the application of fuzzy TOPSIS, sensitivity analysis was used. The literature suggests many methods in performing sensitivity analysis, and most of these studies are focused on weights of the alternatives or criteria (Shi et al., 2007). In the present study, sensitivity analysis was performed by changing the weights and identifying its effect on the ranks of the attributes. This process is aimed to establish the criticality of the criteria considered for the assessment (Triantaphyllou \& Sanchez, 1997). This method proposes an assessment of sensitivity in terms of "smallest change". Such alteration in the weight of the criteria will cause a change in the ranking of the attributes. In the present study, the weights equal to value one initially assigned for each criterion, and then the ranks are reassessed. Furthermore, the weight of the "condition after road construction" criteria has increased at an incremental value of 0.1 , while the weight of the accident severity criteria is kept at 1 .

The procedure followed here in this study assumes that both the criteria are not more than twice as important as each other. From the assessment, it is observed that the ranks obtained for the attributes are robust even after a change in the weights. Spearman's rank correlation coefficient was used to assess the extent to which the proposed method employed reflects the necessary information embedded. It is also deduced from the sensitivity analysis that the model can be consistent with any change in the data set employed in the study. Table 13 below summarizes Spearman's rank correlation coefficients between the original ranks and the ranks obtained after altering the criteria weights.
Table 13. Spearman's rank correlation coefficients

\begin{tabular}{|l|c|}
\hline \multicolumn{1}{|c|}{ Criteria } & $\begin{array}{c}\text { Spearman's rank } \\
\text { correlation coefficient }\end{array}$ \\
\hline Condition before road construction & 0.998 \\
\hline Condition after road construction & 1.000 \\
\hline
\end{tabular}

\section{Conclusions}

Governments of developed as well as developing countries all over the world, emphasize achieving sustainable rural development. The development of rural road infrastructure, in integration with supportive schemes, policies, and workshops, can play a significant role in rural development. Improvement in physical mobility helps in achieving sustainability outcomes in the context of rural areas. The idea of sustainable development can only be achieved when the concerned decision-makers have a good view of the impacts due to rural road construction. The living conditions of rural individuals improve significantly with the improvement in rural roads, as they provide enhanced access to necessary education and health services, markets. In consideration of development, rural roads also provide rural inhabitants with useful information that help to reduce their vulnerability. They assist them to participate in social development programs. Improvement of road infrastructure also leads to a sustainable livelihood, which allows the rural inhabitants to recover and handle the economic shocks and stresses. However, apart from positive impacts, the rural roads also have negative impacts such as the depletion of air quality, change in vegetation cover, noise pollution, the transmission of diseases, increase in road accidents, etc.

Therefore, assessment of negative impacts and positive impacts is important for sustainable rural development. However, literature on the evaluation of the adverse effects lacks tools to identify the negative impacts. There are no instruments/techniques for assessing the adverse effects 
of rural roads that can provide comprehensive conclusions. The present study explored the application of fuzzy TOPSIS, improved the FWA technique and developed a novel tool to assess the possible attributes that contribute to negative impacts on the target population due to the implementation of rural road infrastructure. The attitudes/perceptions of rural road users have been quantified to evaluate each attribute's effects that impact rural development. They are assessed based upon their relative significance, the results obtained from both the methods are compared, and final attributes are identified by considering the intersection of both approaches. Of all the criteria selected for the study, the major negative impact of rural road construction has been an increase in road accidents. Thus, the concerned decision- and policy-makers are to devise corrective action plans to prevent more accidents in the future.

The tool developed herein can be employed by the concerned authorities involved in rural policymaking and administration. As the data on the attributes contributing to negative impacts are imprecise and uncertain, the proposed model addresses the vagueness of such data. Also, depending upon the requirement of the assessment, the tool can be conditioned and formulated. This will help the concerned decision-makers to frame the tool following the data set. The proposed tool can be employed at a wider level rather than just a region. Furthermore, it will assist the concerned local authorities to devise corrective action plans so that proper allocation of funds can be planned effectively. However, from the future scope/viewpoint of the study, the cost-benefit analysis can be performed in amalgamation with the applied tool. Necessary educative actions can be implemented through policies, programs, and workshops, thereby helping to reduce the number of road accidents.

\section{Acknowledgements}

The authors acknowledge the support provided by the National Rural Infrastructure Development Agency (NRIDA), Ministry of Rural Development, Government of India, New Delhi, and Birla Institute of Technology and Science Pilani to carry out the research work. The authors also gratefully acknowledge the Deanship of Scientific Research, King Khalid University (KKU), Abha-Asir, Kingdom of Saudi Arabia, for funding this research work under the grant number R.G.P2./89/41.

\section{Funding}

This work was supported by the Deanship of Scientific Research, King Khalid University (KKU), Abha-Asir, Kingdom of Saudi Arabia, under Grant number R.G.P2./89/41.

\section{Conflict of interest}

The authors declare that they have no conflict of interest.

\section{References}

Abur, C. C., Ademoyewa, G. R., \& Damkor, M. (2015). Impact of rural roads infrastructure on the income and productivity of household's farmers in North Central Nigeria. Research Journal of Agricultural and Environmental Management, 4(10), 451-458.

Aderamo, A. J., \& Magaji, S. A. (2010). Rural transportation and the distribution of public facilities in Nigeria: a case of Edu local government area of Kwara State. Journal of Human Ecology, 29, 171-179.

https://doi.org/10.1080/09709274.2010.11906260

Aggarwal, S. (2018) Do rural roads create pathways out of poverty? Evidence from India. Journal of Development Economics, 133, 375-395. https://doi.org/10.1016/j.jdeveco.2018.01.004

Asif, F. (2012). The promise of rural roads. Transportation research circular E-C167: Review of the role of low-volume roads in rural connectivity, poverty reduction, crisis management, and livability. Transportation Research Board, Washington, DC.

Asomani-Boateng, R., Fricano, R. J., Adarkwa, F. (2015). Assessing the socio-economic impacts of rural road improvements in Ghana: a case study of Transport Sector Program Support (II). Case Studies on Transport Policy, 3(4), 355-366. https://doi.org/10.1016/j.cstp.2015.04.006

Barnow, B. S., \& King, C. T. (2000). Improving the odds: Increasing the effectiveness of publicly funded training. The Urban Institute, Washington, DC.

Bellman, R. E., \& Zadeh, L. A. (1970). Decision-making in a fuzzy environment. Management Science, 17(4), B-141-B-164. https://doi.org/10.1287/mnsc.17.4.B141

Berechman, J. (2009). The evaluation of transportation investment projects. Routledge.

https://doi.org/10.4324/9780203873281

Binswanger, H. P., Khandker, S. R., \& Rosenzweig, M. R. (1993). How infrastructure and financial institutions affect agricultural output and investment in India. Journal of Development Economics, 41(2), 337-366.

https://doi.org/10.1016/0304-3878(93)90062-R

Chen, S. H., \& Hsieh, C. H. (2000). Representation, ranking, distance, and similarity of LR type fuzzy number and application. Australian Journal of Intelligent Information Processing Systems, 6(4), 217-229.

Chen, S., Saeed, T. U., \& Labi, S. (2017). Impact of road-surface condition on rural highway safety: A multivariate random parameters negative binomial approach. Analytic Methods in Accident Research, 16, 75-89.

https://doi.org/10.1016/j.amar.2017.09.001

Chen, S., Saeed, T. U., Alinizzi, M., Lavrenz, S., \& Labi, S. (2019). Safety sensitivity to roadway characteristics: A comparison across highway classes. Accident Analysis \& Prevention, 123, 39-50. https://doi.org/10.1016/j.aap.2018.10.020

Chen, X., Hellinga, B., Chang, C., \& Fu, L. (2015). Optimization of headways with stop-skipping control: a case study of bus rapid transit system. Journal of Advanced Transportation, 49(3), 385-401. https://doi.org/10.1002/atr.1278 
Daigle, P. (2010). A summary of the environmental impacts of roads, management responses, and research gaps: A literature review. Journal of Ecosystems \& Management, 10(3), 65-89.

Desapriya, E., Kerr, J. M., Hewapathirane, D. S., Peiri,s D., Mann, B., Gome,s N., Peiris, K., Scime, G., \& Jones, J. (2012). Bull bars and vulnerable road users. Traffic Injury Prevention, 13, 8692. https://doi.org/10.1080/15389588.2011.624143

Feldacker, C., Ennett, S. T., \& Speizer, I. (2011). It's not just who you are but where you live: an exploration of community influences on individual HIV status in rural Malawi. Social Science \& Medicine, 72(5), 717-725.

https://doi.org/10.1016/j.socscimed.2011.01.003

Forman, R. T., \& Alexander, L. E. (1998). Roads and their major ecological effects. Annual Review of Ecology and Systematics, 29, 207-231. https://doi.org/10.1146/annurev.ecolsys.29.1.207

Gachassin, M., Najman, B., \& Raballand, G. (2010). The impact of roads on poverty reduction: a case study of Cameroon. World Bank, Washington, DC.

Hall, T., \& Tarko, A. P. (2019). Adequacy of negative binomial models for managing safety on rural local roads. Accident Analysis \& Prevention, 128, 148-158. https://doi.org/10.1016/j.aap.2019.03.001

Hine, J., Sasidharan, M., Eskandari Torbaghan, M., Burrow, M. P. N., \& Usman, K. (2019). Evidence on impact of rural roads on poverty and economic development (K4D Helpdesk Report). Institute of Development Studies, Brighton, UK.

Kahraman, C., Yasin Ateş, N., Çevik, S., Gülbay, M., \& Ayça Erdoğan, S. (2007). Hierarchical fuzzy TOPSIS model for selection among logistics information technologies. Journal of Enterprise Information Management, 20(2), 143-68. https://doi.org/10.1108/17410390710725742

Khandker, S. B., Koolwal, G., \& Samad, H. (2009). Handbook on impact evaluation: quantitative methods and practices. World Bank, Washington, DC. https://doi.org/10.1596/978-0-8213-8028-4

Kanuganti, S., Sarkar, A. K., \& Singh, A. P. (2016). Evaluation of access to health care in rural areas using enhanced two-step floating catchment area (E2SFCA) method. Journal of Transport Geography, 56, 45-52.

https://doi.org/10.1016/j.jtrangeo.2016.08.011

Kanuganti, S., Dutta, B., Sarkar, A. K., \&, Singh, A. P. (2017). Development of a need-based approach for rural road network planning. Transportation in Developing Economies, 2, 314. https://doi.org/10.1007/s40890-017-0044-y

Labi, S., Faiz, A., Saeed, T. U., Alabi, B. N. T., \& Woldemariam, W. (2019). Connectivity, accessibility, and mobility relationships in the context of low-volume road networks. Transportation Research Record: Journal of the Transportation Research Board, 2673(12), 717-727.

https://doi.org/10.1177/0361198119854091

Liang, X., \& Meng, X. (2019). An extended FTOPSIS method for freeway route selection in the pre-feasibility study stage. Physica A: Statistical Mechanics and its Applications, 526, 120871. https://doi.org/10.1016/j.physa.2019.04.107

Lopera, M. A., Mitnik, O. A., \& Yañez, P. (2017). Impact evaluation in transport. Inter-American Development Bank, Washington, DC.

Luce, C. H., \& Wemple, B. C. (2001). Introduction to special issue on hydrologic and geomorphic effects of forest roads. Earth Surface Processes and Landforms: The Journal of the British Geomorphological Research Group, 26, 111-113.

https://doi.org/10.1002/1096-9837(200102)26:2<111::AIDESP165>3.0.CO;2-2
Madej, M. A. (2001). Erosion and sediment delivery following removal of forest roads. Earth Surface Processes and Landforms: The Journal of the British Geomorphological Research Group, 26, 175-190. https://doi.org/10.1002/10969837(200102)26:2<175::AID-ESP174>3.0.CO;2-N

Mashiri, M. (2004). Community responses to HIV/AIDS along transit corridors and areas of intense transport operations in eastern and southern Africa. Reports to the UK Department for International Development (Transport Knowledge and Research program). IFRTD/CSIR Transportek, Karen Nairobi, Kenya.

Morris, C. N., \& Ferguson, A. G. (2006). Estimation of the sexual transmission of HIV in Kenya and Uganda on the transAfrica highway: the continuing role for prevention in high risk groups. Sexually Transmitted Infections, 82(5), 368-371. https://doi.org/10.1136/sti.2006.020933

Muralidharan, K., \& Prakash, N. (2017). Cycling to school: Increasing secondary school enrolment for girls in India. American Economic Journal: Applied Economics, 9(3), 321-350. https://doi.org/10.1257/app.20160004

Pedrycz, W. (1994). Why triangular membership functions?. Fuzzy Sets and Systems, 64(1), 21-30.

https://doi.org/10.1016/0165-0114(94)90003-5

Porter, G. (2012). Reflections on a century of road transport developments in West Africa and their (gendered) impacts on the rural poor. EchoGeo, 20.

https://doi.org/10.4000/echogeo.13116

Rand, J. (2011). Evaluating the employment-generating impact of rural roads in Nicaragua. Journal of Development Effectiveness, 3(1), 28-43.

https://doi.org/10.1080/19439342.2010.545890

Riverson, J., Gaviria, J., \& Thriscutt, S. (1991). Rural roads in subSaharan Africa: lessons from World Bank experience (Report No.WTP 141). World Bank, Washington, DC.

Saeed, T. U., Hall, T., Baroud, H., \& Volovski, M. J. (2019). Analyzing road crash frequencies with uncorrelated and correlated random-parameters count models: An empirical assessment of multilane highways. Analytic Methods in Accident Research, 23, 100101. https://doi.org/10.1016/j.amar.2019.100101

Shi, Y., Olson, D. L., \& Stam, A. (2007). Advances in multiple criteria decision making and human systems management: Knowledge and wisdom. IOS Press.

Sinha, K. C., \& Labi, S. (2011). Transportation decision-making: Principles of project evaluation and programming. Wiley \& Sons.

Singh, A. P., Dhadse, K., \& Ahalawat, J. (2019). Managing water quality of a river using an integrated geographically weighted regression technique with fuzzy decision-making model. Environmental Monitoring and Assessment, 191(6), 378. https://doi.org/10.1007/s10661-019-7487-z

Suresh, K. P. (2011). An overview of randomization techniques: an unbiased assessment of outcome in clinical research. Journal of Human Reproductive Sciences, 4, 8-11. https://doi.org/10.4103/0974-1208.82352

Trombulak, S. C., \& Frissell, C. A. (2000). Review of ecological effects of roads on terrestrial and aquatic communities. Conservation Biology, 14, 18-30. https://doi.org/10.1046/j.1523-1739.2000.99084.x

Tsunokawa, K., \& Hoban, C. (Eds.). (1997). Roads and the environment: a handbook. World Bank, Washington, DC. https://doi.org/10.1596/0-8213-4031-X

Tunde, A. M., \& Adeniyi, E. E. (2012). Impact of road transport on agricultural development: a Nigerian example. Ethiopian 
Journal of Environmental Studies and Management, 5, 232238. https://doi.org/10.4314/ejesm.v5i3.3

Triantaphyllou, E., \& Sánchez, A. (1997). A sensitivity analysis approach for some deterministic multi-criteria decision-making methods. Decision Sciences, 28, 151-194. https://doi.org/10.1111/j.1540-5915.1997.tb01306.x

Van de Walle, D. (2009). Impact evaluation of rural road projects. Journal of Development Effectiveness, 1, 15-36. https://doi.org/10.1080/19439340902727701

Wagale, M., \& Singh, A. P. (2019). The application of adaptive neuro-fuzzy inference system and fuzzy Delphi technique to assess socio-economic impacts of construction of rural roads. Transport and Telecommunication Journal, 20(4), 325-345. https://doi.org/10.2478/ttj-2019-0027

Wagale, M., Singh, A. P., \& Sarkar, A. K. (2019a). Impact of rural road construction on the local livelihood diversification: Evidence from Pradhan Mantri Gram Sadak Yojana in Jhunjhunu district, India. GeoJournal, 85, 961-978.

https://doi.org/10.1007/s10708-019-10007-3

Wagale, M., Singh, A. P., \& Sarkar, A. K. (2019b). Exploring rural road impacts using fuzzy multi-criteria approach. In S. Pulugurtha, I. Ghosh, \& S. Biswas (Eds.), Lecture notes in civil engineering: Vol. 34. Advances in transportation engineering (pp. 1-12). Springer. https://doi.org/10.1007/978-981-13-7162-2_1

Wagale, M., \& Singh, A. P., \& Sarkar, A.K. (2021). Socio-economic impacts of low-volume roads using a mixed-method approach of PCA and Fuzzy-TOPSIS. International Review for Spatial Planning and Sustainable Development, 9(2), 112-133. https://doi.org/10.14246/irspsda.9.2_112

Wang, Y. M., Chin, K. S., Poon, G. K., \& Yang, J. B. (2009). Risk evaluation in failure mode and effects analysis using fuzzy weighted geometric mean. Expert Systems with Applications, 36(2), 1195-1207. https://doi.org/10.1016/j.eswa.2007.11.028

Wondemu, K. A., \& Weiss, J. (2012). Rural roads and development: evidence from Ethiopia. European Journal of Transport and Infrastructure Research, 12(4).

https://doi.org/10.18757/ejtir.2012.12.4.2977 